\title{
Association Between Hyperuricemia and Acute Ischemic Stroke in Patients at a Tertiary Care Hospital
}

Muhammad Irfan ${ }^{1}$, Wajid Jawaid ${ }^{1}$, Owais Hashmat ${ }^{2}$, Oamar Nisa ${ }^{1}$, Dipanty R. Khastoori II ${ }^{1}$, Naila Shahbaz ${ }^{1}$

1. Neurology, Dow University of Health Sciences, Karachi, PAK 2. Neurology, Aga Khan University, Karachi, PAK

Corresponding author: Muhammad Irfan,gemini_dow@hotmail.com

\section{Abstract \\ Introduction}

Stroke is the most debilitating of neurologic diseases. The rationale of the current study was to determine the association between hyperuricemia and ischemic stroke to establish a local perspective.

\section{Methods}

A total of 148 patients at a tertiary care hospital in Pakistan who fulfilled the inclusion criteria were enrolled in the study and then equally distributed into two study groups consisting of cases and controls ( $n=74$ in each group). In this study, there were 36 (48.6\%) participants in the case group with hyperuricemia and ischemic stroke and 18 (24.3\%) participants in the control group with hyperuricemia. The mean and standard deviations were computed for quantitative variables such as age, body mass index (BMI), and duration of stroke. Frequencies and percentages for the qualitative variables such as gender, hypertension, type 2 diabetes (T2D), dyslipidemia, smoking status, socioeconomic status, educational level, and hyperuricemia were calculated. The chi-square test was applied to compare both groups, with $p \leqslant 0.05$ indicating significance. The odds ratio was also calculated to determine the association between case and control. Effect modifiers were controlled through stratification of age, gender, BMI, duration of stroke, hypertension, T2D, dyslipidemia, socioeconomic status, educational level, and smoking status to determine the effect of these on outcome variables. A post-stratification chi-square test was applied, with $p \leqslant 0.05$ indicating statistical significance.

\section{Results}

In our study, stratification of hyperuricemia into cases and controls was performed for age, gender, T2D, hypertension, dyslipidemia, smoking status, socioeconomic status, and educational status. The maximum results were significant, with high strength of association between both groups. In the case group, the frequency of elevated uric acid was significantly higher than that of the control group. A comparison of hyperuricemia indicated $p=0.002$, with an odds ratio of 2.95 , which showed that elevated uric acid could be taken as a predictor of ischemic stroke. The uric acid level was significantly higher in men than in women.

Review began 09/28/2020 Review ended 10/07/2020 Published 10/11/2020

\section{() Copyright 2020}

Irfan et al. This is an open access article distributed under the terms of the Creative Commons Attribution License CC-BY 4.0., which permits unrestricted use, distribution, and reproduction in any medium, provided the original author and source are credited.
Additionally, hyperuricemia was associated with dyslipidemia. In patients with ischemic stroke, there was a significant association between serum uric acid level and T2D, hypertension, and smoking.

\section{Conclusions}

This study showed that the prevalence of hyperuricemia in patients with ischemic stroke was significantly higher as compared to the healthy population. Hyperuricemia can be considered as a risk factor for ischemic stroke because of its high prevalence in ischemic stroke patients. Our study explored the relationship between stroke and hyperuricemia and enabled increased understanding for caregivers so that effective management plans can be formulated for patients with ischemic stroke to prevent adverse outcomes.

Categories: Internal Medicine, Neurology, Epidemiology/Public Health

Keywords: ischemic stroke, cases, controls, hyperuricemia, hypertension, diabetes mellitus, dyslipidemia

\section{Introduction}

Stroke is one of the most debilitating neurologic diseases and is the second most common cause of death and the third leading cause of disability in developed and developing countries [1]. According to a study, approximately 13.7 million new cases of stroke occur each year [2]. No large-scale epidemiological studies are available to determine the true incidence of stroke in Pakistan. The estimated annual incidence is $250 / 100,000$, translating to 350,000 new cases every year [3]. Commonly quoted fatality rates are $17 \%$ at six months and $22 \%$ at one year. Many risk factors are involved in the development of stroke, including hypertension, cigarette smoking, hyperlipidemia, and diabetes [4]. 
Serum uric acid is considered as a risk marker for ischemic stroke. It is associated with endothelial dysfunction, coronary artery disease, and peripheral arterial disease, as well as nonalcoholic fatty liver disease [5]. Hyperuricemia has been linked with macrovascular and microvascular diseases in type 2 diabetes (T2D) patients. However, high serum uric acid level as an independent risk factor for cardiovascular disease, including stroke, is controversial [6]. Uric acid is the end-product of purine metabolism. It is a physiological free radical scavenger and one of the significant contributors of plasma antioxidant capacity. It plays a dual role, both as a prooxidant and as an antioxidant. Urate, the soluble form of uric acid, can scavenge the superoxide and the hydroxyl radicals and can chelate the transition metals [7]. In a study on the American population with acute stroke, those with higher serum levels of uric acid were more debilitated, with more recurrences and cardiovascular accidents [8]. A three-month follow-up of stroke patients in England indicated greater mortality for those with higher uric acid levels [9]. In one study conducted on patients of non-embolic ischemic stroke, higher uric acid levels resulted in enhanced risk of recurrence of stroke and associated complications [10]. Increased risks of both cerebrovascular and cardiovascular events were associated with hyperuricemia [11].

Some studies suggest antioxidant properties of uric acid offering neuroprotective role [12]. Similarly, one study noted lower mortality as well as complications in animal models with administration of uric acid [13]. Interestingly, less intense stroke lesions were noted in patients with higher uric acid levels [14]. Khalil et al. found that $23.3 \%$ of the patients with hyperuricemia had ischemic stroke in the case group and $6.7 \%$ of patients in the control group had hyperuricemia and no stroke [15].

Because of the ambiguity in previous studies on hyperuricemia, it is difficult to determine whether high uric acid levels are beneficial or detrimental or whether they can be used as a risk marker for ischemic stroke. Thus, we performed a retrospective study using hospital patients in Pakistan to determine the association between hyperuricemia and ischemic stroke.

\section{Materials And Methods}

We conducted a six-month case-control study of consenting stroke patients treated at the Department of Neurology in Civil Hospital, Karachi, Pakistan. Inclusion criteria included all patients of either sex aged 30 to 60 years admitted with ischemic stroke confirmed by a brain computed tomography (CT) scan showing a hypodense area. Patients who did not consent to be included were excluded from the study along with those with body mass index $(\mathrm{BMI})>30 \mathrm{~kg} / \mathrm{m}^{2}$, a history of alcohol consumption, history of hypothyroidism or hyperthyroidism, myeloproliferative or lymphoproliferative disorders, renal impairment, chronic obstructive pulmonary disease, chronic liver disease, or congestive cardiac failure. Patients on medications such as thiazide or aspirin were also excluded. Patients with acute ischemic stroke were designated as case-patients and those without were labeled as control-patients. A brief history of the duration of illness and demographic information was taken from each patient and confirmed by an attendant. Blood samples were collected after 12-hour overnight fasting in a sterile manner for serum uric acid levels by our team on the first day of admission. The collected samples were sent to the same laboratory for biochemical analysis. All findings were entered into a proforma.

Data were analyzed using SPSS for Windows, Version 16.0 (SPSS Inc., Chicago, IL, USA). Mean and standard deviations were calculated for the quantitative variables such as age, BMI, and duration of stroke. Frequencies and percentages for the qualitative variables such as sex, hypertension, T2D, dyslipidemia, smoking status, socioeconomic status, educational level, and hyperuricemia were calculated.

Patients were considered as having ischemic stroke if they met two or more of the following criteria: Glasgow coma scale score $<15$, inability to move one or more limbs, and a CT scan showing a hypodense area. We defined hyperuricemia as uric acid levels $>7 \mathrm{mg} / \mathrm{dL}$ for male patients or $>6 \mathrm{mg} / \mathrm{dL}$ for female patients. Hypertension was defined as patients with systolic blood pressure $>140 \mathrm{mmHg}$ or diastolic blood pressure $>90 \mathrm{mmHg}$ and treated for more than five years. Patients with T2D had glycated hemoglobin > 6.5\%. Patients with any one of the following were considered as having dyslipidemia: total cholesterol $>200$ $\mathrm{mg} / \mathrm{dL}$, serum triglyceride levels $>150 \mathrm{mg} / \mathrm{dL}$, low-density lipoprotein (LDL) > $100 \mathrm{mg} / \mathrm{dL}$, or high-density lipoprotein (HDL) $<40 \mathrm{mg} / \mathrm{dL}$. Patients who smoke at least five cigarettes per day for at least one year were deemed as smokers, and patients who had quit smoking for at least one year after being a smoker or those who had never smoked were deemed as non-smokers.

We applied the chi-square test to compare both groups, and a p-value of $\leqslant 0.05$ was considered significant. We also calculated the odds ratio to see the association between case and control patients. Effect modifiers were controlled by stratifying age, gender, BMI, duration of stroke, hypertension, T2D, dyslipidemia, socioeconomic status, educational level, and smoking status to assess their impact on the outcome variables. We applied a post-stratification Chi-square test and considered a p-value of $\leqslant 0.05$ as statistically significant. For sample size calculation, we used OpenEpi with alpha $=5 \%$, power of the test 1 -beta $=80$, anticipated population proportion $1=23.3 \%$, and anticipated population proportion $2=6.7 \%$. The calculated sample size was a total of 148 patients, with 74 patients in each group. We applied non-probability consecutive sampling. 


\section{Cureus}

\section{Results}

A total of 148 patients who fulfilled the inclusion criteria were enrolled in the study and were then equally distributed into two study groups. Table 1 shows that patients who were included in the study had an age range of 30 to 60 years, and the mean age of patients in the case group was 46.4 years (standard deviation [SD]: 9.0 years). The mean age of patients in the control group was 45.7 years (SD: 9.3 years). Table 2 shows the age group distribution, which was similar for each group. There were slightly more male patients than female patients in both groups (Table 3).

\begin{tabular}{|c|c|c|c|c|c|}
\hline & $\mathbf{n}$ & Minimum & Maximum & Mean & Standard Deviation \\
\hline \multicolumn{6}{|c|}{ Age (years) } \\
\hline Case & 74 & 30 & 60 & 46.4 & 9.04 \\
\hline Control & 74 & 30 & 60 & 45.7 & 9.36 \\
\hline \multicolumn{6}{|c|}{ BMI $\left(k g / m^{2}\right)$} \\
\hline Case & 74 & 22.5 & 29.6 & 24.2 & 3.7 \\
\hline Control & 74 & 21.5 & 27 & 23.9 & 4.6 \\
\hline \multicolumn{6}{|c|}{ Duration of stroke (in hours) } \\
\hline Case & 74 & 3 & 12 & 4.5 & 2.6 \\
\hline Control & 74 & - & $\begin{array}{ll}- \\
-\end{array}$ & - & - \\
\hline
\end{tabular}

TABLE 1: Descriptive statistics of quantitative variables $(n=148)$

Abbreviation: BMI, body mass index

\begin{tabular}{|c|c|c|c|}
\hline Groups & Age (years) & Frequency & Percentage \\
\hline \multirow{3}{*}{ Case } & $30-50$ & 46 & $62.2 \%$ \\
\hline & $51-60$ & 28 & $38.8 \%$ \\
\hline & Total & 74 & 100.0 \\
\hline \multirow{3}{*}{ Control } & $30-50$ & 46 & $62.2 \%$ \\
\hline & $51-60$ & 28 & $38.8 \%$ \\
\hline & Total & 74 & 100.0 \\
\hline
\end{tabular}

TABLE 2: Age distribution $(n=148)$ 


\section{Cureus}

\begin{tabular}{|c|c|c|c|}
\hline Groups & Gender & Frequency & Percentage \\
\hline \multirow{3}{*}{ Case } & Female & 33 & 44.6 \\
\hline & Male & 41 & 55.4 \\
\hline & Total & 74 & 100.0 \\
\hline \multirow{3}{*}{ Control } & Female & 30 & 40.5 \\
\hline & Male & 44 & 59.5 \\
\hline & Total & 74 & 100.0 \\
\hline
\end{tabular}

TABLE 3: Gender distribution $(n=148)$

Most patients $(71.6 \% ; \mathrm{n}=53)$ in the case group had $\mathrm{T} 2 \mathrm{D}$, whereas a smaller majority of patients in the control group $(51.4 \%, \mathrm{n}=38$ ) had T2D (Table 4). Hypertension was more common in the case group (64.9\%; $n=48$ ) than the control group (Table 5). Table 6 presents the distribution of smoking status. Dyslipidemia was more prevalent in the case group than in the control group (Table 7). Table 8 presents the socioeconomic status distribution, and Table 9 shows the distribution of educational status. In Table 10, the distribution of hyperuricemia showed that 36 (48.6\%) participants had hyperuricemia in the case group and 18 (24.3\%) participants had hyperuricemia in the control group, indicating that the frequency of elevated uric acid was significantly higher as compared to the control group ( $\mathrm{p}=0.002$; odds ratio: 2.95$)$.

\begin{tabular}{|c|c|c|c|}
\hline Groups & T2D & Frequency & Percentage \\
\hline \multirow{3}{*}{ Case } & Yes & 53 & $71.6 \%$ \\
\hline & No & 21 & $28.4 \%$ \\
\hline & Total & 74 & $100 \%$ \\
\hline \multirow{3}{*}{ Control } & Yes & 38 & $51.4 \%$ \\
\hline & No & 36 & $48.6 \%$ \\
\hline & Total & 74 & $100 \%$ \\
\hline
\end{tabular}

TABLE 4: Distribution of T2D $(n=148)$

Abbreviation: T2D, type 2 diabetes

\begin{tabular}{|c|c|c|c|}
\hline Groups & Hypertension & Frequency & Percentage \\
\hline \multirow{3}{*}{ Case } & Yes & 48 & $64.9 \%$ \\
\hline & No & 26 & $35.1 \%$ \\
\hline & Total & 74 & $100 \%$ \\
\hline \multirow{3}{*}{ Control } & Yes & 30 & $40.54 \%$ \\
\hline & No & 44 & $59.46 \%$ \\
\hline & Total & 74 & $100 \%$ \\
\hline
\end{tabular}

TABLE 5: Distribution of hypertension $(n=148)$ 


\section{Cureus}

\begin{tabular}{|c|c|c|c|}
\hline Groups & Smoking & Frequency & Percentage \\
\hline \multirow{3}{*}{ Case } & Yes & 40 & $54.1 \%$ \\
\hline & No & 34 & $45.9 \%$ \\
\hline & Total & 74 & $100 \%$ \\
\hline \multirow{3}{*}{ Control } & Yes & 31 & $41.9 \%$ \\
\hline & No & 43 & $58.1 \%$ \\
\hline & Total & 74 & $100 \%$ \\
\hline
\end{tabular}

TABLE 6: Distribution of smoking $(n=148)$

\begin{tabular}{|c|c|c|c|}
\hline Groups & Dyslipidemia & Frequency & Percentage \\
\hline \multirow{3}{*}{ Case } & Yes & 45 & $60.8 \%$ \\
\hline & No & 29 & $39.2 \%$ \\
\hline & lotal & 74 & $100 \%$ \\
\hline \multirow{3}{*}{ Control } & Yes & 35 & $47.3 \%$ \\
\hline & No & 39 & $52.7 \%$ \\
\hline & lotal & 74 & $100 \%$ \\
\hline
\end{tabular}

TABLE 7: Distribution of dyslipidemia $(n=148)$

\begin{tabular}{|c|c|c|c|}
\hline Groups & Socioeconomic Status & Frequency & Percentage \\
\hline \multirow{3}{*}{ Case } & Lower class & 20 & $27.02 \%$ \\
\hline & Middle class & 34 & $45.94 \%$ \\
\hline & Upper class & 20 & $27.02 \%$ \\
\hline \multirow{3}{*}{ Control } & Lower class & 12 & $16.21 \%$ \\
\hline & Middle class & 22 & $29.72 \%$ \\
\hline & Upper class & 40 & $54.05 \%$ \\
\hline
\end{tabular}




\section{Cureus}

\begin{tabular}{|c|c|c|c|}
\hline Groups & Educational Status & Frequency & Percentage \\
\hline \multirow{4}{*}{ Case } & Illiterate & 3 & $4.05 \%$ \\
\hline & Primary & 10 & $13.51 \%$ \\
\hline & Secondary & 15 & $20.27 \%$ \\
\hline & Higher & 46 & $62.16 \%$ \\
\hline \multirow{4}{*}{ Control } & Illiterate & 5 & $6.75 \%$ \\
\hline & Primary & 13 & $17.56 \%$ \\
\hline & Secondary & 21 & $28.37 \%$ \\
\hline & Higher & 35 & $47.29 \%$ \\
\hline
\end{tabular}

TABLE 9: Distribution of educational status $(n=148)$

\begin{tabular}{|c|c|c|c|}
\hline Groups & Hyperuricemia & Frequency & Percentage \\
\hline \multirow{3}{*}{ Case } & No & 38 & 51.4 \\
\hline & Yes & 36 & 48.6 \\
\hline & Total & 74 & 100.0 \\
\hline \multirow{3}{*}{ Control } & No & 56 & 75.7 \\
\hline & Yes & 18 & 24.3 \\
\hline & Total & 74 & 100.0 \\
\hline
\end{tabular}

TABLE 10: Distribution and comparison of hyperuricemia in both groups $(n=148)$

Tables 11-18 show the stratification of hyperuricemia in cases and controls with respect to age, gender, T2D, hypertension, dyslipidemia, smoking status, socioeconomic status, and educational status. The maximum results were significant and exhibited high strength of association between both of the groups. 


\section{Cureus}

\begin{tabular}{|c|c|c|c|c|c|c|}
\hline \multirow[t]{2}{*}{ Age } & & & \multicolumn{2}{|c|}{ Hyperuricemia } & \multirow[t]{2}{*}{ Total } & \multirow[t]{2}{*}{ p-Value, OR } \\
\hline & & & Yes & No & & \\
\hline \multirow{3}{*}{$30-50$ years } & & Case & 20 & 20 & 40 & \multirow{3}{*}{$0.0083,3.333$} \\
\hline & & Control & 12 & 40 & 52 & \\
\hline & Total & 32 & 60 & 92 & & \\
\hline \multirow{3}{*}{$51-60$ years } & & Case & 16 & 18 & 34 & \multirow{3}{*}{$0.143,2.370$} \\
\hline & & Control & 6 & 16 & 22 & \\
\hline & Total & 22 & 34 & 56 & & \\
\hline \multirow{3}{*}{ Total } & & Case & 36 & 38 & 74 & \multirow{3}{*}{$0.002,2.95$} \\
\hline & & Control & 18 & 56 & 74 & \\
\hline & Total & 54 & 94 & 148 & & \\
\hline
\end{tabular}

TABLE 11: Stratification of hyperuricemia in both groups with regard to age $(n=148)$

Values were obtained by applying the chi-square test. $p$-Value $=0.002$. OR $=2.95$.

Abbreviation: OR, odds ratio

\begin{tabular}{|c|c|c|c|c|c|c|}
\hline \multirow[t]{2}{*}{ Gender } & & & \multicolumn{2}{|c|}{ Hyperuricemia } & \multirow[t]{2}{*}{ Total } & \multirow[t]{2}{*}{ p-Value, OR } \\
\hline & & & Yes & No & & \\
\hline \multirow{3}{*}{ Male } & & Case & 22 & 16 & 38 & \multirow{3}{*}{$0.008,5.09$} \\
\hline & & Control & 10 & 37 & 47 & \\
\hline & Total & 32 & 53 & 85 & & \\
\hline \multirow{3}{*}{ Female } & & Case & 14 & 22 & 36 & \multirow{3}{*}{$0.446,1.511$} \\
\hline & & Control & 8 & 19 & 27 & \\
\hline & Total & 22 & 41 & 63 & & \\
\hline \multirow{3}{*}{ Total } & & Case & 36 & 38 & 74 & \multirow{3}{*}{$0.002,2.95$} \\
\hline & & Control & 18 & 56 & 74 & \\
\hline & Total & 54 & 94 & 148 & & \\
\hline
\end{tabular}

TABLE 12: Stratification of hyperuricemia in both groups with regard to gender $(n=148)$

Abbreviation: OR, odds ratio 


\section{Cureus}

\begin{tabular}{|c|c|c|c|c|c|c|}
\hline \multirow[t]{2}{*}{ T2D } & & & \multicolumn{2}{|c|}{ Hyperuricemia } & \multirow[t]{2}{*}{ Iotal } & \multirow[t]{2}{*}{ p-Value, OR } \\
\hline & & & Yes & No & & \\
\hline \multirow{3}{*}{ Yes } & & Case & 21 & 15 & 36 & \multirow{3}{*}{$0.003,3.73$} \\
\hline & & Control & 15 & 40 & 55 & \\
\hline & Total & 36 & 55 & 91 & & \\
\hline \multirow{3}{*}{ No } & & Case & 15 & 23 & 38 & \multirow{3}{*}{$0.079,3.478$} \\
\hline & & Control & 3 & 16 & 19 & \\
\hline & Total & 18 & 39 & 57 & & \\
\hline \multirow{3}{*}{ Total } & & Case & 36 & 38 & 74 & \multirow{3}{*}{$0.002,2.95$} \\
\hline & & Control & 18 & 56 & 74 & \\
\hline & Tot & 54 & 94 & 148 & & \\
\hline
\end{tabular}

TABLE 13: Stratification of hyperuricemia in both groups with regard to T2D $(n=148)$ Abbreviations: T2D, type 2 diabetes; OR, odds ratio

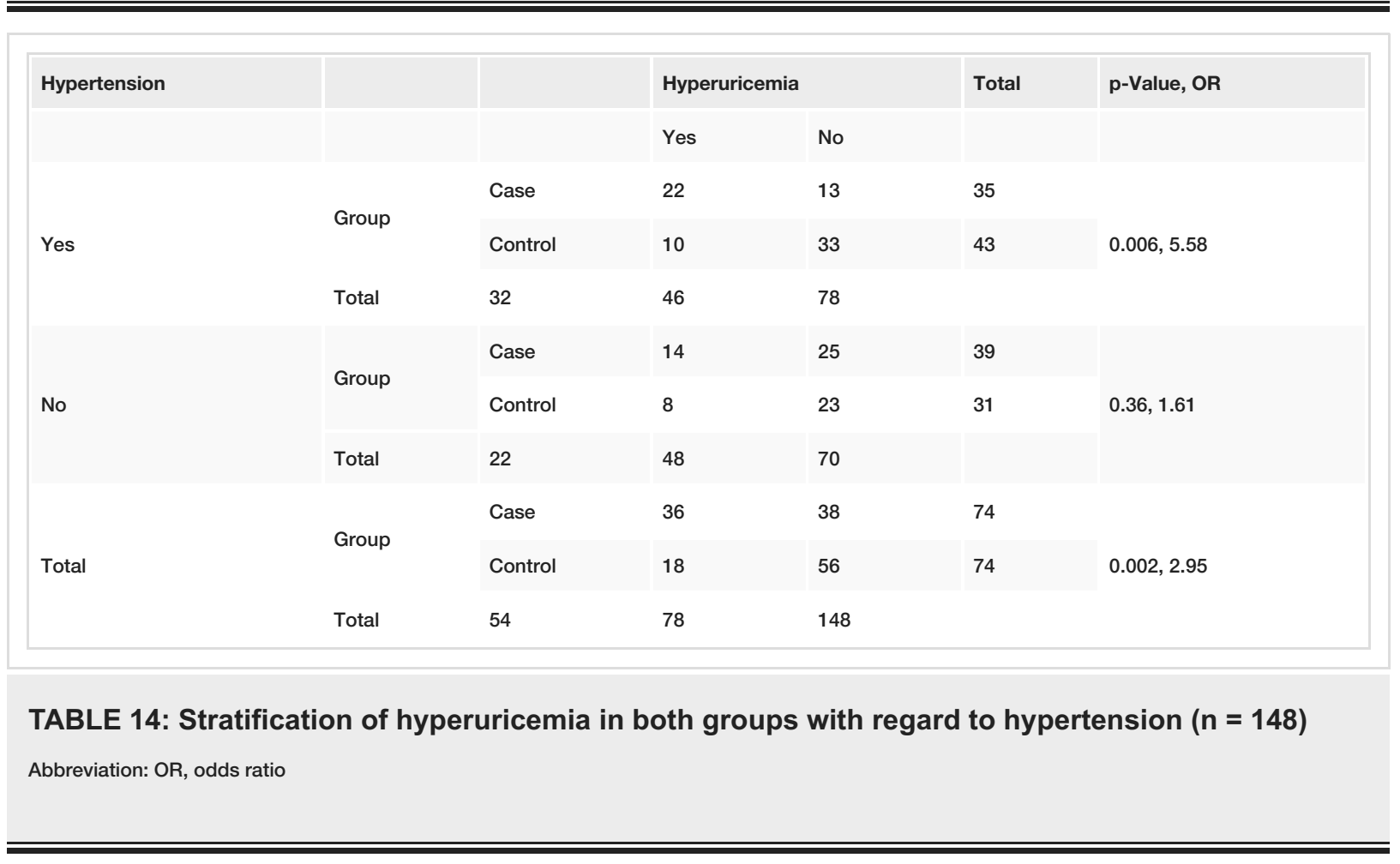




\section{Cureus}

\begin{tabular}{|c|c|c|c|c|c|c|}
\hline \multirow[t]{2}{*}{ Smoking } & & & \multicolumn{2}{|c|}{ Hyperuricemia } & \multirow[t]{2}{*}{ Total } & \multirow[t]{2}{*}{ p-Value, OR } \\
\hline & & & Yes & No & & \\
\hline \multirow{3}{*}{ Yes } & & Case & 26 & 19 & 45 & \multirow{3}{*}{$0.52,1.37$} \\
\hline & & Control & 13 & 13 & 26 & \\
\hline & Total & 39 & 32 & 71 & & \\
\hline \multirow{3}{*}{ No } & & Case & 10 & 19 & 29 & \multirow{3}{*}{$0.013,4.526$} \\
\hline & & Control & 5 & 43 & 48 & \\
\hline & Total & 15 & 62 & 77 & & \\
\hline \multirow{3}{*}{ Total } & & Case & 36 & 38 & 14 & \multirow{3}{*}{$0.002,2.95$} \\
\hline & & Control & 18 & 56 & 74 & \\
\hline & Total & 54 & 94 & 148 & & \\
\hline
\end{tabular}

TABLE 15: Stratification of hyperuricemia in both groups with regard to smoking $(n=148)$

Abbreviation: OR, odds ratio

\begin{tabular}{|c|c|c|c|c|c|c|}
\hline \multirow[t]{2}{*}{ Dyslipidemia } & & & \multicolumn{2}{|c|}{ Hyperuricemia } & \multirow[t]{2}{*}{ Total } & \multirow[t]{2}{*}{$\mathrm{p}$-Value, OR } \\
\hline & & & Yes & No & & \\
\hline \multirow{3}{*}{ Yes } & & Case & 20 & 18 & 38 & \multirow{3}{*}{$0.002,4.72$} \\
\hline & & Control & 8 & 34 & 42 & \\
\hline & Total & 28 & 52 & 80 & & \\
\hline \multirow{3}{*}{ No } & & Case & 16 & 20 & 36 & \multirow{3}{*}{$0.27,1.76$} \\
\hline & & Control & 10 & 22 & 32 & \\
\hline & Total & 26 & 42 & 68 & & \\
\hline \multirow{3}{*}{ Total } & & Case & 36 & 38 & 74 & \multirow{3}{*}{$0.002,2.95$} \\
\hline & & Control & 18 & 56 & 74 & \\
\hline & Total & 54 & 94 & 148 & & \\
\hline
\end{tabular}

TABLE 16: Stratification of hyperuricemia in both groups with regard to dyslipidemia $(n=148)$

Abbreviation: OR, odds ratio 


\section{Cureus}

\begin{tabular}{|c|c|c|c|c|c|c|}
\hline \multirow{2}{*}{ Socioeconomic Status } & & & \multicolumn{2}{|c|}{ Hyperuricemia } & \multirow[t]{2}{*}{ Total } & \multirow[t]{2}{*}{ p-Value, OR } \\
\hline & & & Yes & No & & \\
\hline \multirow{3}{*}{ Lower } & & Case & 10 & 8 & 18 & \multirow{3}{*}{$0.13,3.13$} \\
\hline & & Control & 4 & 10 & 14 & \\
\hline & Total & 14 & 18 & 32 & & \\
\hline \multirow{3}{*}{ Middle } & & Case & 6 & 15 & 21 & \multirow{3}{*}{$0.067,5.00$} \\
\hline & & Control & 2 & 25 & 33 & \\
\hline & Total & 8 & 40 & 56 & & \\
\hline \multirow{3}{*}{ Upper } & & Case & 20 & 10 & 30 & \multirow{3}{*}{$0.48,1.44$} \\
\hline & & Control & 12 & 13 & 25 & \\
\hline & Total & 32 & 28 & 60 & & \\
\hline \multirow{3}{*}{ Total } & & Case & 36 & 38 & 74 & \multirow{3}{*}{$0.002,2.95$} \\
\hline & & Control & 18 & 56 & 74 & \\
\hline & otal & 54 & 94 & 148 & & \\
\hline
\end{tabular}

TABLE 17: Stratification of hyperuricemia in both groups with regard to socioeconomic status (n = 148)

Abbreviation: OR, odds ratio.

\begin{tabular}{|c|c|c|c|c|c|c|}
\hline \multirow[t]{2}{*}{ Educational Status } & & & \multicolumn{2}{|c|}{ Hyperuricemia } & \multirow[t]{2}{*}{ Total } & \multirow[t]{2}{*}{ p-Value, OR } \\
\hline & & & Yes & No & & \\
\hline \multirow{3}{*}{ Illiterate } & & Case & 4 & 1 & 5 & \multirow{3}{*}{$0.67,2.00$} \\
\hline & & Control & 2 & 1 & 3 & \\
\hline & Total & 6 & 2 & 8 & & \\
\hline \multirow{3}{*}{ Primary } & & Case & 11 & 5 & 16 & \multirow{3}{*}{$0.09,5.50$} \\
\hline & & Control & 2 & 5 & 7 & \\
\hline & Total & 13 & 10 & 23 & & \\
\hline \multirow{3}{*}{ Secondary } & & Case & 12 & 12 & 24 & \multirow{3}{*}{$0.001,14.00$} \\
\hline & & Control & 4 & 56 & 74 & \\
\hline & Total & 32 & 78 & 36 & & \\
\hline \multirow{3}{*}{ Higher } & & Case & 9 & 20 & 29 & \multirow{3}{*}{$0.233,1.89$} \\
\hline & & Control & 10 & 42 & 52 & \\
\hline & Total & 19 & 62 & 81 & & \\
\hline
\end{tabular}

TABLE 18: Stratification of hyperuricemia in both groups with regard to educational status $(\mathrm{n}=$ 148)

Abbreviation: OR, odds ratio

Table 19 shows the stratification of hyperuricemia in cases and controls with respect to BMI, and the 


\section{Cureus}

maximum results were significant and exhibited high strength of association between both of the groups (p = 0.002; odds ratio: 2.95 ). Table 20 shows stratification of hyperuricemia with regard to duration of stroke.

\begin{tabular}{|c|c|c|c|c|c|c|}
\hline \multirow[t]{2}{*}{ BMI } & & & \multicolumn{2}{|c|}{ Hyperuricemia } & \multirow[t]{2}{*}{ Total } & \multirow{2}{*}{ p-Value, OR } \\
\hline & & & Yes & No & & \\
\hline \multirow{3}{*}{$<22$ kg/m² } & & Case & 18 & 10 & 28 & \multirow{3}{*}{$0.001,7.2$} \\
\hline & & Control & 9 & 36 & 45 & \\
\hline & Total & 27 & 46 & 73 & & \\
\hline \multirow{3}{*}{$>22 \mathrm{~kg} / \mathrm{m}^{2}$} & & Case & 18 & 28 & 46 & \multirow{3}{*}{$0.25,1.86$} \\
\hline & & Control & 9 & 26 & 35 & \\
\hline & Total & 26 & 42 & 81 & & \\
\hline \multirow{3}{*}{ Total } & & Case & 36 & 38 & 74 & \multirow{3}{*}{$0.002,2.95$} \\
\hline & & Control & 18 & 56 & 74 & \\
\hline & Total & 54 & 94 & 148 & & \\
\hline
\end{tabular}

TABLE 19: Stratification of hyperuricemia in both groups with regard to BMI $(n=148)$

Abbreviations: BMI, body mass index; OR, odds ratio

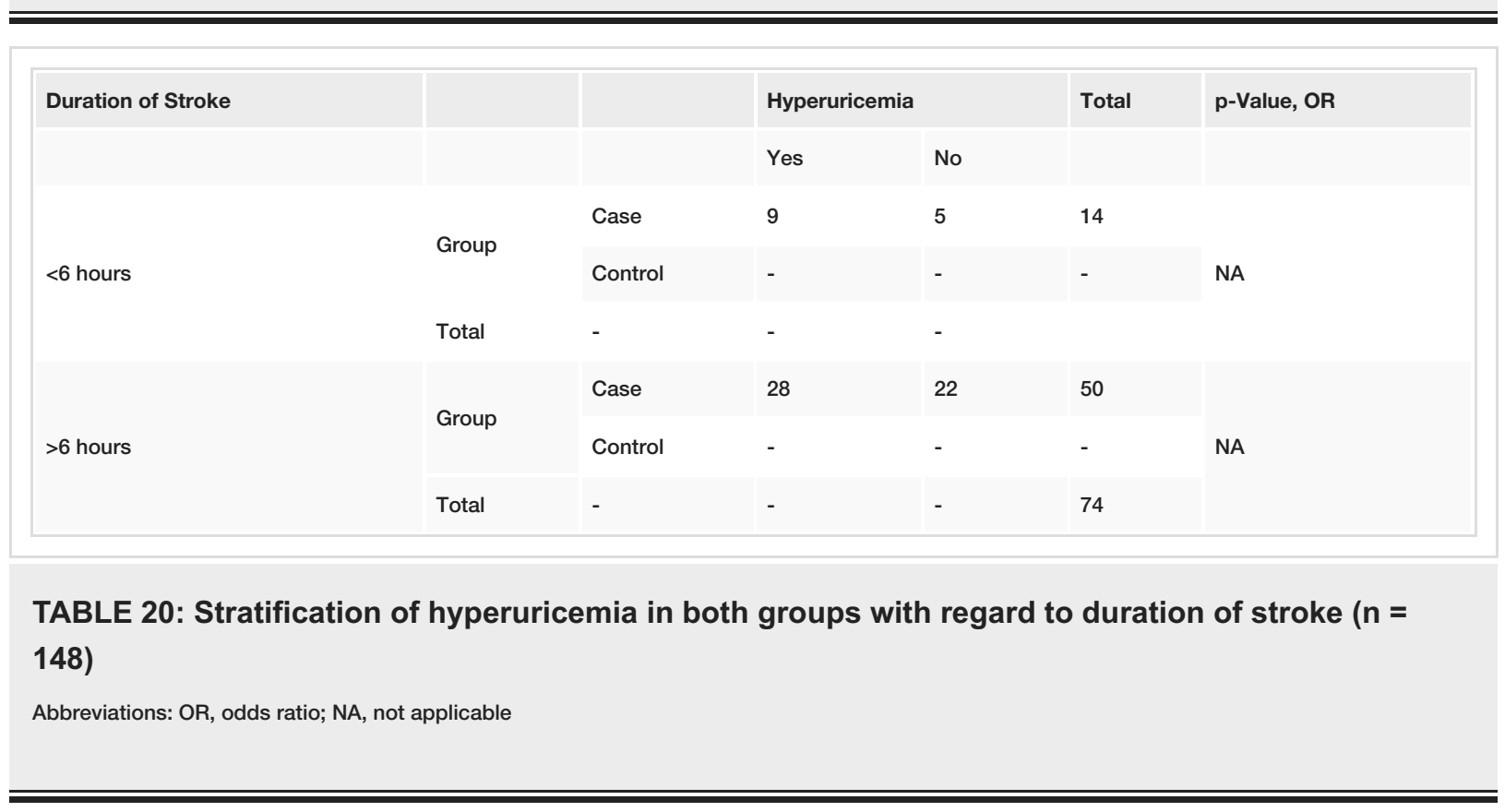

\section{Discussion}

In this study, the serum uric acid levels in patients with acute stroke were noted in relation to the healthy population. The mean serum uric acid level was $5.94( \pm 1.70) \mathrm{mg} / \mathrm{dL}$, and approximately half of the patients were hyperuricemic. According to a large 10-year follow-up study, the prevalence of hyperuricemia in the United States is $20.1 \%$ [16]. Another large study in the Bangkok population showed that the prevalence of hyperuricemia is $24.4 \%$ [17], and a study from the island of Seychelles reported that the prevalence of hyperuricemia is $35.2 \%$ in men and $8.7 \%$ in women [18]. According to these studies, the prevalence of hyperuricemia was significantly higher in patients with acute stroke as compared to the healthy population.

Stroke is one of the main clinical manifestations of cardiovascular disease, and findings from studies investigating the relationship between uric acid and stroke have been inconsistent. Some studies reported a positive independent relationship between uric acid and stroke, whereas others demonstrated that there was no significant relationship between uric acid and stroke occurrence, as discussed below. 
Bansal et al. studied 50 patients with ischemic thrombotic cerebrovascular disease. Hyperuricemia was found in $30 \%$ of the cases, and they concluded that elevated serum uric acid level might play a role in the causation of ischemic thrombotic cerebrovascular disease in general, and especially in patients younger than 40 years [19]. Kim et al. conducted a systematic review and meta-analysis of 16 prospective cohort studies, including 238,449 adults, to assess the association between hyperuricemia and risk of stroke incidence and mortality [5]. They found that hyperuricemia may modestly but significantly increase the risk of both stroke incidence and mortality.

According to the results of Milionis et al., elevated serum uric acid levels were associated with an increased risk of acute ischemic stroke in the elderly [10]. However, in the Syst-Eur trial that included patients with isolated systolic hypertension, no significant relationship was detected between serum uric acid levels and fatal and non-fatal strokes [20]. Moreover, in a middle-aged Japanese population, hyperuricemia was not associated with stroke mortality in 108,284 person-years on follow-up [21]. After Goldberg et al. studied middle-aged men and followed them for 20 years, they determined that there was not a significant correlation between serum uric acid and thromboembolic stroke [22]. Chamorro et al. assessed the prognostic significance of serum uric acid concentration in patients with acute ischemic stroke, and they reported that patients with $\mathrm{T} 2 \mathrm{D}$ had a lower uric acid concentration than other patients and that uric acid concentration was inversely associated with fasting blood glucose [14].

In our study, there was no significant association between serum uric acid level and serum triglyceride, total cholesterol, HDL cholesterol, and LDL cholesterol, but hyperuricemia was associated with serum triglycerides and LDL cholesterol in some studies such as the one by Zavaroni et al. [23] who studied 957 young men and demonstrated that there was a significant positive correlation between serum uric acid levels, and levels of serum triglyceride, total cholesterol, and LDL cholesterol. Moreover, Chamorro et al. [14] reported the association between the serum uric acid level and the amount of serum triglyceride.

The mechanism of this strong association between serum uric acid levels and triglyceride levels is still poorly understood. Although some studies reported the role of genetic factors in the occurrence of gout and hypertriglyceridemia, most researchers noted that hyperuricemia and hypertriglyceridemia might reflect the patient's lifestyle as a part of metabolic syndrome [11].

Different studies assessed the uric acid levels exclusively in patients with ischemic stroke where there was a significant association between the uric acid level and the incidence of acute ischemic stroke $[11,24]$. According to the results of Bos et al., the hazard ratio of elevated serum uric acid levels in ischemic stroke was 1.77 , and in hemorrhagic stroke, it was 1.68 [24].

The role of urate in ischemic stroke is poorly understood. Therefore, the role of uric acid as a risk factor for vascular disease and acute stroke is controversial. Because there is a lack of information, we decided to determine serum uric acid levels in patients with acute stroke and assess its relationship with cardiovascular risk factors. Previous studies have indicated that hyperuricemia predicts ischemic heart disease in nondiabetics $[23,25]$. However, the data relating the risk of hyperuricemia to cerebrovascular disease are limited.

Overwhelming evidence suggests that hyperuricemia is linked to obesity, hypertension, reduced HDL cholesterol [26], hypertriglyceridemia, hyperinsulinemia, and reduced insulin sensitivity [27]. We also observed that this association and the presence of multiple risk factors are likely to explain a substantial part of the increased risk of stroke. However, even after extensive adjustment for cardiovascular risk factors, the serum uric acid remained an independent risk factor for stroke.

Our study had a few limitations. Our study used a smaller sample size of admitted patients compared to other studies we discussed. We also used a relatively short duration and narrow age range (30 to 60 years). Future studies with larger populations, broader age ranges, and longer durations will help mitigate these limitations.

\section{Conclusions}

Our study showed that the prevalence of hyperuricemia in patients with acute ischemic stroke was significantly higher as compared to the healthy population. In terms of gender distribution, uric acid levels were significantly higher in men than in women. Hyperuricemia was also associated with dyslipidemia, and in patients with acute ischemic stroke, there was a significant association between serum uric acid levels, and diabetes mellitus, hypertension, and smoking. Therefore, as determined in our study, due to the high prevalence of hyperuricemia in patients with ischemic stroke, it should be considered as a risk factor for acute ischemic stroke.

\section{Additional Information}

\section{Disclosures}

Human subjects: Consent was obtained by all participants in this study. Animal subjects: All authors have 
confirmed that this study did not involve animal subjects or tissue. Conflicts of interest: In compliance with the ICMJE uniform disclosure form, all authors declare the following: Payment/services info: All authors have declared that no financial support was received from any organization for the submitted work. Financial relationships: All authors have declared that they have no financial relationships at present or within the previous three years with any organizations that might have an interest in the submitted work. Other relationships: All authors have declared that there are no other relationships or activities that could appear to have influenced the submitted work.

\section{References}

1. Feigin VL: Stroke epidemiology in the developing world. Lancet. 2005, 365:2160-2161. 10.1016/S01406736(05)66755-4

2. GBD 2016 Stroke Collaborators: Global, regional, and national burden of stroke, 1990-2016: a systematic analysis for the Global Burden of Disease Study 2016. Lancet Neurol. 2019, 18:439-458. 10.1016/S14744422(19)30034-1

3. Information about stroke. (2006). Accessed: March 5, 2013: http://www.pakstroke.com..

4. Glamcevski MT, Pierson J: Prevelence of and factors associated with poststroke depression: a Malaysian study. J Stroke Cerebrovasc Dis. 2005, 14:157-161. 10.1016/j.jstrokecerebrovasdis.2005.03.006

5. Kim SY, Guevara JP, Kim KM, Choi HK, Heitjan DF, Albert DA: Hyperuricemia and risk of stroke: a systematic review and meta-analysis. Arthritis Rheum. 2009, 15:885-892. 10.1002/art.24612

6. Li M, Hou W, Zhang X, Hu L, Tang Z: Hyperuricemia and risk of stroke: a systematic review and metaanalysis of prospective studies. Atherosclerosis. 2014, 232:265-270. 10.1016/j.atherosclerosis.2013.11.051

7. Patterson RA, Horsley E TM, Leake DS: Prooxidant and antioxidant properties of human serum ultrafiltrates towards LDL: important role of uric acid. J Lipid Res. 2003, 44:512-521. 10.1194/jlr.M200407-JLR200

8. Kanellis J, Johonson RJ: Editorial comment--Elevated uric acid and ischemic stroke: accumulating evidence that it is injurious and not neuroprotective. Stroke. 2003, 34:1956-1957. 10.1161/01.STR.0000081984.07414.EF

9. Iranmanesh F, Sheykholeslami NZ, Gadari F, Ahmady J: Acute ischemic non-embolic stroke and serum level of uric acid. Iran J Neurol. 2012, 11:1-5.

10. Milionis HJ, Kalantzi KJ, Goudevenos JA, Seferiadis K, Mikhailidis DP, Elisaf MS: Serum uric acid levels and risk for acute ischaemic non-embolic stroke in elderly subjects. J Intern Med. 2005, 258:435-441. $10.1111 / \mathrm{j} .1365-2796.2005 .01565 . \mathrm{x}$

11. Hozawa A, Folsom AR, Ibrahim H, Nieto FJ, Rosamond WD, Shahar E: Serum uric acid and risk of ischemic stroke: the ARIC Study. Atherosclerosis. 2006, 187:401-407. 10.1016/j.atherosclerosis.2005.09.020

12. Romanos E, Planas AM, Amaro S, Chamorro A: Uric acid reduces brain damage and improves the benefits of rt-PA in a rat model of thromboembolic stroke. J Cereb Blood Flow Metab. 2007, 27:14-20. 10.1038/sj.jcbfm.9600312

13. Waring WS: Uric acid: an important antioxidant in acute ischemic stroke . QJM. 2002, 95:691-693. 10.1093/qjmed/95.10.691

14. Chamorro Á, Obach V, Cervera Á, Revilla M, Deulofeu R, Aponte HJ: Prognostic significance of uric acid serum concentration in patients with acute ischemic stroke. Stroke. 2002, 33:1048-1052. 10.1161/hs0402.105927

15. Khalil MI, Islam MJ, Ullah MA, et al.: Association of serum uric acid with ischemic stroke. Mymensingh Med J. 2013, 22:325-330.

16. Zhu Y, Pandya BJ, Choi HK: Comorbidities of gout and hyperuricemia in the US general population: NHANES 2007-2008. Am J Med. 2012, 125:679-687. 10.1016/j.amjmed.2011.09.033

17. Uaratanawong S, Suraamornkul S, Angkeaw S, Uaratanawong R: Prevalence of hyperuricemia in Bangkok population. Clin Rheumatol. 2011, 7:887-893. 10.1007/s10067-011-1699-0

18. Conen D, Wietlisbach V, Bovet P, Shamlaye C, Riesen W, Paccaud F, Burnier M: Prevalence of hyperuricemia and relation of serum uric acid with cardiovascular risk factors in a developing country. BMC Public Health. 2004, 4:9. 10.1186/1471-2458-4-9

19. Bansal BC, Gupta RR, Bansal MR, Prakash C: Serum lipids and uric acid relationship in ischemic thrombotic cerebrovascular disease. Stroke. 1975, 6:304-307. 10.1161/01.str.6.3.304

20. De Leeuw PW, Thijs L, Birkenhager WH, et al.: Prognostic significance of renal function in elderly patients with isolated systolic hypertension: results from the Syst-Eur trial. J Am Soc Nephrol. 2002, 13:2213-2222. 10.1097/01.asn.0000027871.86296.92

21. Sakata K, Hashimoto T, Ueshima H, Okayama A: Absence of an association between serum uric acid and mortality from cardiovascular disease: NIPPON DATA 80, 1980-1994. Eur J Epidemiol. 2001, 17:461-468. 10.1023/a:1013735717961

22. Goldberg RJ, Burchfiel CM, Benfante R, Chiu D, Reed DM, Yano K: Lifestyle and biologic factors associated with atherosclerotic disease in middle-aged men. 20-year findings from the Honolulu Heart Program. Arch lntern Med. 1995, 155:686-694. 10.1001/archinte.1995.00430070036004

23. Zavaroni I, Bonora E, Pagliara M, et al.: Risk factors for coronary artery disease in healthy persons with hyperinsulinemia and normal glucose tolerance. N Engl J Med. 1989, 320:702-706. 10.1056/NEJM198903163201105

24. Bos MJ, Koudstaal PJ, Hofman A, Witteman JCM, Breteler MMB: Uric acid is a risk factor for myocardial infarction and stroke: the Rotterdam study. Stroke. 2006, 37:1503-1507. 10.1161/01.STR.0000221716.55088.d4

25. Freedman DS, Williamson DF, Gunter EW, Byers T: Relation of serum uric acid to mortality ischemic heart disease: the NHANES I Epidemiologic Follow-up Study. Am J Epidemiol. 1995, 141:637-644. 10.1093/oxfordjournals.aje.a117479

26. Wilson PW, Garrison RJ, Abbott RD, Castelli WB: Factors associated with lipoprotein cholesterol levels: the Framingham study. Arteriosclerosis. 1983, 3:273-281. 10.1161/01.atv.3.3.273 


\section{Cureus}

27. Zavaroni I, Mazza S, Fantuzzi M, et al.: Changes in insulin and lipid metabolism in males with asymptomatic hyperuricemia. Int J Med.1993. 234:25-30. 10.1111/j.1365-2796.1993.tb00700.x 